\author{
Available online at https://www.rjtl.org \\ Volume: 2, Issue: 2, 80-84, 2021 \\ ISSN: $2708-3632$ \\ DOI: https://doi.org/10.46590/rjtl.2021.020202
}

\title{
Sustainable Alternatives for Plastic Packaging used in Apparel E-Tailing.
}

\author{
Sharmitha. B ${ }^{1^{*}}$, Nishali.D ${ }^{1}$, Kushal Singh ${ }^{1}$, S. Kavitha ${ }^{2}$ \\ ${ }^{1}$ B.Tech Scholars, ${ }^{2}$ Assistant Professor, \\ Dept of Fashion Technology, Kumaraguru College of Technology, Coimbatore- 641049, India.
}

\section{Paper History}

Received: March 2021

Accepted: April 2021

Published: May 2021

Corresponding Author

Sharmitha. $B$

balusharmi28@gmail.com

\begin{abstract}
Fashion today is about an obsession with outward image and appearance. Though the door delivery of goods is very useful for modern consumers, it has given rise to some serious environmental challenges due to excessive usage of plastics. To pack the clothes ordered online needs a whole leap of plastic wrap, bubble sheet, thermocol sheet and the list of packaging waste is endless. From polybag to collar band, plastic has a wide range of use in the packaging segment, though recycling and reusing these materials are difficult. Products like corrugated bubble sheet, green wrap, indented kraft paper can be intensive as eco-friendly alternatives for this ecological damage. Though there is room for sustainable modules in the fashion industry, there must be companies and people willing to take up the new ideals. This paper reviews plastic consumption in packaging and its environmental annoyance and the alternatives identified by some fashion brands..
\end{abstract}

Keywords: E-Commerce, Fashion, Plastic Packaging, Sustainable

Citation: Sharmitha. B, Nishali.D, Kushal Singh, S. Kavitha.,"Sustainable Alternatives for Plastic Packaging used in Apparel E-Tailing." Research Journal of Textile and Leather, 2(2), 80-84, 2021.

\section{INTRODUCTION}

India has grown to become one of the fastest-growing e-tail markets in the world. Internet in today's world has reached almost every nook and corner and with added support from the government introducing schemes like the 'Digital India', the internet has paved its way to millions of people reaching thousands of panchayats connected by optical fibres and thus providing access to broadband for millions of users. The increase in internet usage is a major factor influencing the growth and optimisation of ecommerce in several sectors including the apparel sector.

As initially, books and electronics contributed to a major part of e-commerce later with the evolution of internet apparel and lifestyle products [1] joined the e-tail market. Talking about the apparel e-tailing the major hold back from customers is not being able to touch and feel the quality of the merchandise and that ending in a dilemma to confidentially decide whether to buy or skip the product. Although a lot of other initiatives like easy return policy, cash on delivery, exchanges, offers and discounts are put forth in the favour of the customers to encourage them to start shopping [2].

\section{IMPACTS OF E-COMMERCE}

Reduction in greenhouse gas emission is considered a positive environmental effect [3]. Online shopping minimises the frequency of consumers travelling to retail outlets. However, packaging waste is one of the concerns. The most common materials used for packing goods are plastics (polybags, bubble wraps), due to their durability and water-resistant properties. In the end, all the plastic packaging stuff are into the municipal waste [5]. The litter is incinerated or buried under the soil (landfill).

\section{PLASTIC TAINTING IN INDIA}

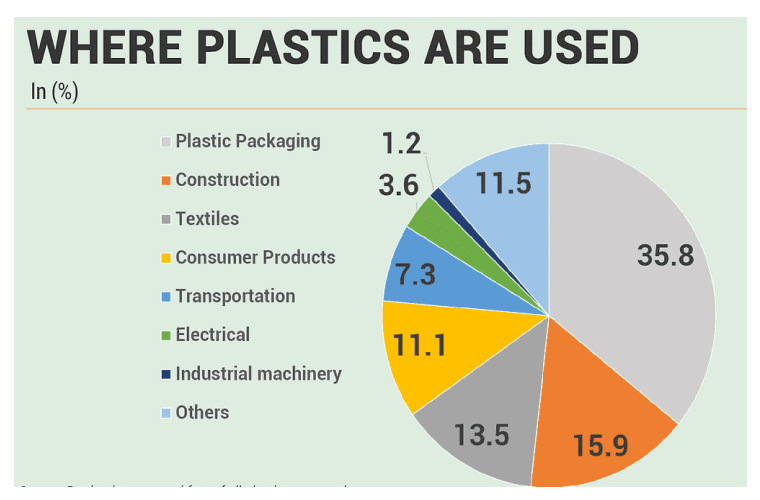

Fig.1. Plastic tainting in India 
Globally, India stands as the 15th biggest plastic polluter with around 26,000 tons of plastic litter. From urban streets to national highways; ponds to rivers; parks to forests, each corner of the country has a huge amount of discarded plastic. As most of the earth, the subcontinent is unable to find a way to dispose of, recycle and reuse plastics. With packaging in concern, the garment industry contributes its share to the litter. While packaging plays a key role in protecting, marketing and online retail clothing, the entire lifecycle of this packaging isn't thought through. Most of the packaging incorporated within these processes includes industrial materials like HDPE, LDPE, polypropylene, PVC and polystyrene; they're often single-use [4] articles. Figure 1 briefs the plastic usage in various segments [6].

\section{CONSUMER AWARENESS}

Society today is more concerned about the future world and its better living. The term sustainability has become a trademark in recent times. The increased advertising of green products has paved the way for consumer consideration of new ideas. The companies: new and existing, are trying out the best ways to promote the business models in a competitive environment along with the sustainability tagline. Our future may look great with environmental concerns going mainstream. A growing demographic of people are on the lookout for environmentally friendly alternatives to traditional products. Today's consumers want companies to feature sustainable and renewable elements in their business models, which can be eventually reflected in their products [7].

This is the evolution of the revolution, which has also impacted the packaging industry. The revolution has increased the scrutiny of the consequences of traditional packaging materials on the environment. The packaging industry is now awakening to the ecological needs and a replacement generation of biodegradable packaging materials just like the corrugated boxes, corn starch has begun to emerge in the market with a promise to bring balance to the environment. Although these initiatives are beneficial to the environment, they also help companies to create better relations with proenvironment customers [10].

\section{ESSENTIAL PACKAGING ARTICLES}

\subsection{Polybag}

Polybag is a plastic pocket, which is used to contain garments to keep the garments intact and dust, dirt or moisture-free. Most plastic bags are heat-sealed at the end or bonded with adhesives. These bags are used from native to international markets.

\subsection{Bubble Wrap}

The thin transparent plastic sheet used to wrap around the fragile items. Accessories like earrings, belts, wallets, clutches, handbags are wrapped with bubble sheet. The wrap controls shock damage by giving a cushioning effect to the product.

\subsection{Hang Tag}

The attachment to an article of merchandise giving information on its cost, material details and care instructions. Plastic Tags are preferred for being durable, strong and waterproof. Though many people think they are just there to tell the customers, the cost of the product, hang tags are a branding opportunity.

\subsection{Tape}

Packing tape is taken into account as a lightweight weight tape utilized as a neighbourhood of a good assortment of uses, usually for fixing boxes and bundles for shipments. The most well-known widths are a couple of inches wide and produced employing a polypropylene or polyester backing.

\subsection{Shirt Packing}

Packaging is considered one of the best ways to promote sales. In shirt packaging, a dozen of materials are used like cardboard, pins, plastic, tissue paper, collar butterfly, collar support and collar stays. This packaging keeps the shirt secure till it reaches the consumers.

\section{ALTERNATIVE SOLUTION FOR A BETTER FUTURE}

\subsection{Hemp Plastic Packaging}

The urge for green packaging has led to the development of hemp plastics. Many brands are in search of environment-friendly resources as the world is depleting its fossil fuel count. Hemp plastic [8] seems to be a good alternative for these companies as they are both environmentally beneficial and cost-effective. The single-use plastics are replaced with hemp plastics. While it's still a new field to enter, there are many reasons to opt-out of hemp packaging.

Hemp plastic packaging objectives:

- Hemp plastic is biodegradable.

- The requirement of fossil fuels is zero for production. The amount of water is less for hemp processing.

- Hemp is a better source of raw materials.

\subsection{Glassine Bags}

The glassine bags are made through a process called supercalendering. The main feature of the bag is to 
have a smooth and glossy look. The raw material is paper. The bags are recyclable, biodegradable, transparent enough to scan a barcode through and durable.

\subsection{Bubble Wrap Substitutes}

\subsubsection{Corrugated Bubble}

Corrugated bubble (fig.2) is produced using destroyed paper material, made out of the unusable part of layered sheets from the delivery boxes [9]. Along these lines, in addition to the fact that the corrugated bubble is $100 \%$ reused, recyclable and compostable, it's likewise upcycled.

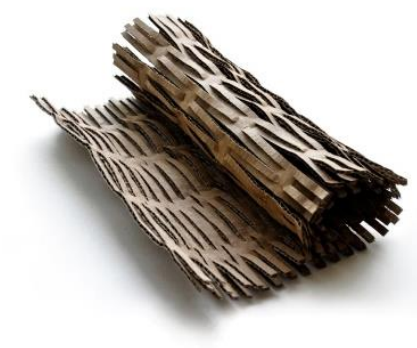

Fig.2. Corrugated Bubble

\subsubsection{Green Wrap}

Green Wrap (fig.3) offers 'padding and cushioned' impact as bubble wrap. The benefit is that it's biodegradable, compostable and completely recyclable [9]. It artfully shapes round the items, giving a lovely presentation. Furthermore, it occupies considerably less space than the horrendous plastic air pockets.

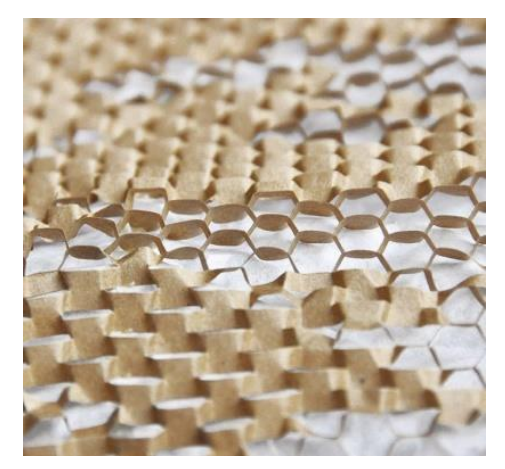

Fig.3. Green Wrap

\subsubsection{Intended Kraft Paper}

Indented kraft(fig.4) is one of the more grounded and sturdier bundling paper choices [9]. It offers strong assurance, however equal to the degree of padding as Green Wrap and customary bubble wrap. Then again, it's operationally less difficult than Green Wrap. The paper is frequently utilized for wrapping something that needs a little measure of padding, (for example, 1 or 2 glass jugs of essential oils).

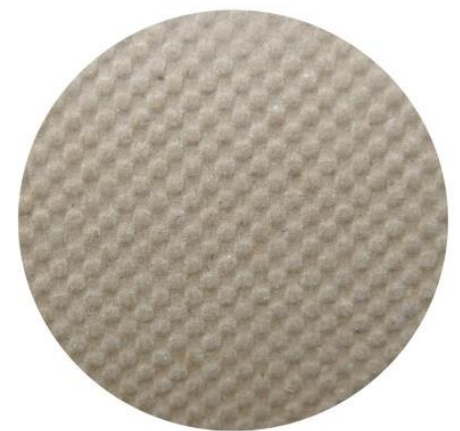

Fig.4. Intended Kraft Paper

\section{D) Paper Bubble Wrap}

The product (fig.5) offers an eco-friendly substitute in protective bundling without involving any kind of reduction in quality and standard. The feature highlight is to supply shock absorbing security against outside harm. It guarantees dependable padding all-through travel and its recyclable characteristics offer a finish of life, the eco-friendly answer for plastic waste.

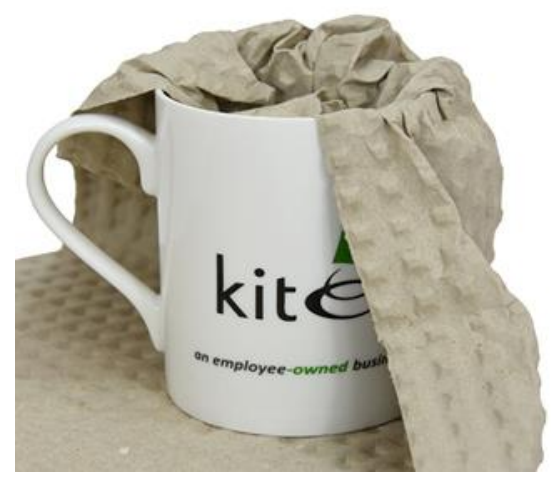

Fig.4. Paper Bubble Wrap

\subsection{Stone Paper Instead of Plastic Tags}

Stone paper is made of crushed stone powder. The staple is taken from the stone quarry waste. The production of this paper uses less water and energy. Also, the carbon dioxide release is less. The benefits of stone paper are:

- The amount of water needed to produce a stone paper is zero, whereas 350 litres of water are required for making $10 \mathrm{~kg}$ of normal paper.

- Stone paper manufacturing needs only $15 \%$ of the energy required by ordinary paper.

- The carbon dioxide emission is about $67 \%$ lesser than the normal level.

- The paper is both waterproof and resistant.

- High durability index.

\subsection{Paper Tape}

Paper tape is biodegradable and $100 \%$ recyclable without the extra process of going to separate the plastic tape from it during the mulching process, this 
makes it the proper environmentally-friendly alternative to plain packing tape.

\section{BRANDS WITH SUSTAINABLE RETAIL PACKAGING}

\subsection{Zara's Zero Waste}

The Fashion Lead has thought of making 100\% recycling of all packing materials. So, for all the orders which the store is serving to customers, it is using recycled cardboard boxes. The purpose is to reduce the waste gradually and make it zero and use all of them with proper recycling. The bag used to send goods to customers is $100 \%$ recycled bags [10]. With this, the volume of wastage will get reduced.

\subsection{Amazon}

Amazon India has gradually reduced the use of plastic bags for delivery. Now they have completely stopped using single-use plastic bags. Instead, they have started to use bubble bags and air pillows.

The bags used for customer delivery are now recycled paper bags are recycled through the box which is used for bulk packing for warehouse transfers. Also, they have included biodegradable wraps and tapes for all types of delivery. Amazon is one of the main retailers that has moved to this concept for customer's delivery packing.

\subsection{Pink Boutique's Sweet and Sustainable Approach}

A famous women's wear retailer has recently moved to eco-friendly packaging for all customer delivery package. Now their packages are made of sugarcane which is $100 \%$ recyclable and eco-friendly biodegradable.

\subsection{Maggie Marliyn's Root Starch Bags}

The non-plastic bag used in the brand is made of plant materials (root starch) and it is $99.5 \%$ degradable. This bag is completely biodegradable if we are put it in water. It doesn't contain any plastic or any other harmful materials so it's environment friendly.

\subsection{Reformation}

Reformation has started the implementation of environment-friendly bags and set an example for other online firms. They have started using vegetable bags that can be $100 \%$ biodegradable. With this it doesn't produce any harmful wastes, it's completely decomposed and get mixed with the soil and it doesn't affect the soil's fertility. Also, they have used such biodegradable products for marking hangers, covers, etc.

\subsection{ASOS (As Seen On Screen)}

ASOS has proposed and initiated an environmentfriendly packaging for their logistics and end-user delivery. By doing this they have gradually decreased the use of plastics and started using recycled bags for luggage purpose. They have also started working on recycling the customer bags which will again increase the usage of environmentfriendly packages and will be cost-effective [11].

\section{CONCLUSION}

Consumers are satisfied with the availability of a wide range of products over the internet, yet they do not care about environmental damage. E-commerce is not as greener as thought. The negative side of online shopping can be turned right with new ideas and innovations. Brands must include earth-friendly packaging articles and consumers should accept the change for a better tomorrow $[12,13]$. So, the future lies in the hands of consumers, corporate companies and government policies.

\section{REFERENCES}

[1]. Sudeshna Mukherjee. (2015). Environmental and social impact of fashion: Towards an eco-friendly, ethical fashion. International Journal of Interdisciplinary and Multidisciplinary Studies 2(3) 22-35.

[2]. Urvashi Tandon. (2021). Predictors of online shopping in India: an empirical investigation. Journal of Marketing Analytics 9(2) 65-79. doi: 10.1057/s41270020-00084-6.

[3]. Sílvia Escursell., Pere Llorach., M Blanca Roncero. (2020). Sustainability in ecommerce packaging: A review. Journal of cleaner production $280(1)$.

doi: 10.1016/j.jclepro.2020.124314.

[4]. Till Zimmermann., Rebecca Bliklen. (2020). Single-use vs. reusable packaging in ecommerce: comparing carbon footprints and identifying break-even points. GAIAEcological Perspectives for Science and Society 29 (3) 176-183. doi: 10.14512/gaia.29.3.

[5]. J.H. Song., R.J. Murphy., R. Narayan., G.B.H. Davies. (2009). Biodegradable and compostable alternatives to plastics. Philosophical Transactions of The Royal Society B Biological Sciences 3642127 2139. doi: 10.1098/rstb.2008.0289.

[6]. V Chandrashekar. (2018). In India's largest city, a ban on plastics faces big obstacles. Yale Environment 360, 155-160. Article: e360.yale.edu. 
[7]. K.Chueamuangphan., $\mathrm{P}$ Kashyap., C Visvanathan. (2020). Packaging Waste from E-Commerce: Consumers' Awareness and Concern. Sustainable Waste Management: Policies and Case Studies 1 27-41. doi: 10.1007/978-981-13-7071-7_3.

[8]. Ali Asghar Modi., Rehmatullah Shahid., Muhammad Usman Saeed., Tanzila Younas. (2018). Hemp is the Future of Plastics. E3S Web of conferences 451. doi: 10.1051/e3scconf/20185103002.

[9]. https://www.kitepackaging.co.uk/blog/theres -no-bursting-our-bubble-introducing-ournew-eco-friendly-paper-bubble-wrap.

[10]. Seo, Kyoungah., Suh, Seunghee. (2019). A study on the characteristics and social values of vegan fashion in H\&M and Zara. The Korean society of fashion business 23(6) 86100. doi: $10.12940 / \mathrm{jfb} .2019 .23 .6 .86$.

[11]. Hye-Shin Kim., Martha L Hall. (2015). Green brand strategies in the fashion industry: Leveraging connections of the consumer, brand, and environmental sustainability. Sustainable Fashion Supply Chain Management, 31-45. doi: 10.1007/978-3-319-12703-3_2.

[12]. Marie-Cécile Cervellon., Anne-Sophie Wernerfelt. (2012). Knowledge sharing among green fashion communities online: Lessons for the sustainable supply chain. Journal of Fashion Marketing and Management 16 (2) 176-192. doi: 10.1108/13612021211222860.

[13]. Bruna Villa Todeschini., Daniela Callegarode-Menezes., Marcelo Nogueira Cortimiglia., Antonio Ghezzi. (2017). Innovative and sustainable business models in the fashion industry: Entrepreneurial drivers, opportunities, and challenges.Business Horizons 60 759-770. doi: 10.1016/j.bushor.2017.07.00. 